\title{
Effect of hydration with oral water on nonstress test in a hospital, Turkey: a randomized controlled trial
}

\author{
Yeter Şener \\ Faculty of Health Sciences, Yozgat Bozok University, Yozgat, Turkey \\ Hüseyin Aksoy \\ Kayseri City Hospital, Kayseri, Turkey, and \\ Mürüvvet Başer \\ Faculty of Health Sciences, Erciyes University, Kayseri, Turkey
}

\begin{abstract}
Purpose - The aim of this study was to assess the effect of hydration with oral water on non-stress test (NST). Design/methodology/approach - The study was conducted as single-blinded and randomized controlled. Healthy and outpatient 32 - to 40 -week pregnant women who were aged 19 and older were included in the study. Intervention group pregnant women $(n=66)$ drank $500 \mathrm{ccs}$ of water before the NST, and no attempt was made to the control group $(n=66)$. The NST parameters of the groups with fetal heart rate (FHR), variability, acceleration, deceleration, reactivity and nonreactivity were evaluated.

Findings - Both groups were found to be similar in terms of their descriptive characteristics and variables related to pregnancy $(p>0.05)$. The median FHR was 130.0 in the intervention group, 140.0 in the control group $(p<0.001)$, and the median number of the acceleration was 6.0 in the intervention group and 4.0 in the control group $(p<0.001)$. In terms of the median number of decelerations, the groups were similar $(p>0.05)$.

Originality/value - It was found that hydration with oral water had an effect on NST parameters of FHR and the number of accelerations. However, it was observed that the FHR was within the normal range in both groups. It was thought that it tended to increase the number of accelerations.
\end{abstract}

Keywords Nonstress test, Fetus, Pregnancy, Turkey

Paper type Research paper

\section{Introduction}

One of the important diagnostic tests applied in the prenatal period is the nonstress test (NST) [1]. NST can be defined as recording fetal heart sounds using electronic fetal monitorization and tracking the relationship between fetal movements and heart rate [2]. The NST evaluates the well-being of the fetus by assessing the fetus using variability, acceleration, deceleration, fetal heart rate (FHR), reactivity and nonreactivity parameters [3]. In addition to being a painless test that does not require any invasive procedure, it is thought to be risk-free for both the mother and the fetus [4].

In a healthy pregnancy that continues normally, a healthy fetus is active during the pregnancy. With every movement of the fetus in the womb, an acceleration in FHR occurs. The fact that fetal heartbeats are accelerating during each activity that the fetus creates is an

(C) Yeter Şener, Hüseyin Aksoy and Mürüvvet Başer. Published in Journal of Health Research. Published by Emerald Publishing Limited. This article is published under the Creative Commons Attribution (CC BY 4.0) licence. Anyone may reproduce, distribute, translate and create derivative works of this article (for both commercial and non-commercial purposes), subject to full attribution to the original publication and authors. The full terms of this licence may be seen at http://creativecommons.org/licences/by/4.0/ legalcode

The authors would like to thank Ferhan Elmalı for statistical analysis.

Received 25 December 2020 Revised 24 January 2021 6 March 2021

Accepted 19 March 2021 hydration with oral water 
JHR

36,4

608

indication of fetal well-being. Because this situation shows that the fetus is not affected by hypoxia in the womb, there is no damage to the central and autonomic nervous systems and their integrity [5].

There are many factors that affect fetal movement patterns and uteroplacental perfusion when performing the NST. One of these factors is hydration [6]. In addition, the European Food Safety Authority (EFSA) states that recommended total water intake increases during pregnancy. For pregnant women, EFSA recommend the same amount of water intake as nonpregnant women as well as an increase proportional to the increase in energy intake [7]. Adequate fluid intake has a positive effect on the blood flow to the fetus by increasing the blood volume. As a result of the increased blood flow to the fetus, fetal activity increases, and this increases the possibility of a positive NST result [6]. There are studies in the literature demonstrating that ensuring maternal hydration has positive effects on maternal health, pregnancy status and pregnancy outcomes, hence on the fetus [8-11].

In previous studies that were conducted using the NST results, a set of methods have been tried for fetal well-being. These methods include BL67 point stimulation, chocolate or orange juice, cocoa or caffeine, halogen light and vibroacoustic stimulation, acupressure, music, maternal position and other similar methods [12-18]. However, among these, none of these studies investigated the effect of hydration with oral water on NST parameters. In this respect, the aim of this study was to assess effect of hydration with oral water on NST.

H1. Hydration with oral water affects FHR.

H2. Hydration with oral water affects the number of accelerations.

H3. Hydration with oral water affects the number of decelerations.

H4. Hydration with oral water affects the reactive NST result.

\section{Methods}

This study was conducted as a randomized controlled, single-blind, experimental study. The research was carried out in the NST outpatient clinic of a public hospital in Kayseri province. There are three NST rooms in the outpatient clinic where the research is conducted. In the outpatient clinic, NST is applied to approximately 40 pregnant women a day, and it provides service every weekday between 08.00 and16.00.

\section{Study sampling}

The patients who applied to the NST outpatient clinic, took outpatient care and were at the 32-40th week of gestation were accepted for the research. To reveal the medium effect size difference between the two groups, it was decided to work with 132 volunteers who meet the research criteria, 66 in each group with 5\% type 1 error and $80 \%$ power. Groups were randomized in the electronic environment with equal numbers of participants in each group.

\section{Inclusion criteria for the research}

(1) Being 19 years old and older,

(2) Being a healthy pregnant at the 32-40th week of the gestation and

(3) Outpatient care.

\section{Exclusion criteria for the research}

(1) Multiple pregnancies,

(2) Having systemic disease (congestive cardiac failure, renal failure, thyroid, etc.), 
(3) Being in the category of risky pregnancies (preeclampsia, early membrane rupture, gestational diabetes, polyhydramnios, oligohydramnios, etc.) and

(4) Having a defined risk factor in the fetus.

Requirements to be met before the NST

At least two hours before the NST application;

(1) To have eaten

(2) To have not smoked and not been in a smoking environment,

(3) To have not consumed alcohol,

(4) To have not consumed caffeine,

(5) To have not done exercise (trekking, etc.) and

(6) Having urinated just before the NST,

\section{Data collection}

Pregnant Information Form and NST Findings Information Form were used to collect data.

Pregnant Information Form: It consisted of questions determining the descriptive characteristics and variables related to pregnancy according to the literature [18-20].

NST Findings Information Form: FHR, variability, acceleration, deceleration, reactivity and nonreactivity were recorded in this form.

\section{Pre-application of data collection tools}

Preliminary application of data collection tools was done with ten pregnant women who came to the NST outpatient clinic of the study and were not included in the study. In the preapplication process, the clarity and applicability of the questions used in the survey were evaluated. After the preapplication, it was determined whether the forms used in the research were clear and understandable. Pregnant women who participated in the preapplication were not included in the study.

In this study conducted between November 2019 and December 2019, the Pregnant Information Form was filled prior to NST for both groups. In light of the literature [7, 10, 21, 22] and expert opinions, it was decided that hydration with oral water was going to be with $500 \mathrm{cc}$ 's of intake, and that NST will be performed $15 \mathrm{~min}$ after the hydration with oral water. Then, 500 ccs of water was given to the intervention group, and they were ensured to drink it completely. After 15 min elapsed, the pregnant women were taken to the left side position and the NST was performed. On the other hand, the NST was taken by giving the left side position to the control group without administering water. For each group, the NST Findings Information Form was filled after NST. NST results obtained were evaluated by the same Obstetrician and Gynecologist. As the researcher (Obstetrician and Gynecologist) interpreting the results was not aware of the intervention and control groups, the study was conducted as a single blind study.

The data were evaluated in the IBM SPSS Statistics Standard Concurrent User V 25 (IBM Corp., Armonk, New York, USA) statistical package program. Descriptive statistics were given as the number of units $(n)$, percent $(\%)$, mean \pm standard deviation, median $(\mathrm{M}), 25$ th percentile (P1), 75th percentile (P3). The normal distribution of data of numerical variables was evaluated with the Shapiro Wilk normality test and Q- Q graphs. The homogeneity of the variances was evaluated by the Levene test. Comparisons between groups for variables not normally distributed were made with the Mann-Whitney U test. The exact method of the Pearson chi-square test was used to compare the groups with categorical variables. The value 
JHR

36,4 $p<0.05$ was considered statistically significant. Comparisons between groups for age, number of pregnancies and number of live births were evaluated using independent two samples $t$-test.

\section{Ethical issue}

Within the scope of the research, written permission was obtained from the Ethical Board of Erciyes University Faculty of Medicine (Resolution No: 2019/728 and Date: 23.10.2019) and from the relevant institutions for the preliminary and actual implementation of the research.

\section{Results}

While the average age of the pregnant women participating in the study was $26.62 \pm 5.44$ in the intervention group, it was $28.08 \pm 5.32$ in the control group. It was determined that $47.1 \%$ of the intervention group, $45.6 \%$ of the control group only completed primary education, $87.9 \%$ of the intervention group and $90.9 \%$ of the control group were unemployed. It was determined that the groups were similar in terms of age, educational status, employment status, and there was no statistically significant difference between them $(\phi>0.05$; Table 1$)$.

While the average of the number of pregnancies and the average of the number of live births were $2.51 \pm 1.17$ and $1.18 \pm 1.05$, respectively, in the intervention group, these were $2.71 \pm 1.51$ and $1.33 \pm 1.07$, respectively, in the control group $(\phi>0.05)$. The median gestational week and the median amount of daily oral water intake of the participants were 36.0 and 1.5 liters in the intervention group, respectively, and 37.0 and 1.5 liters in the control group $(p>0.05$; Table 2$)$.

There was variability in both groups participating in the NST evaluation. The presence of accelerations was $95.5 \%$ in the intervention group and $92.4 \%$ in the control group. While the presence of deceleration was $39.4 \%$ in the intervention group, it was $45.5 \%$ in the control group. In terms of the NST result, the reactivity was $93.9 \%$ in the intervention group, while it was $83.3 \%$ in the control group. It was determined that the groups were similar in terms of the presence of variability, acceleration, deceleration and NST results $(\phi>0.05$; Table 3$)$.

Median FHR was found as 130.0 in the intervention group and 140.0 in the control group $(p<0.001)$; the median number of accelerations was found as 6.0 in the intervention group and 4.0 in the control group $(p<0.001)$. In terms of the median number of decelerations, there was no statistically significant difference between the groups $(\phi>0.05$; Table 4$)$.

\begin{tabular}{lcllc}
\hline & \multicolumn{2}{c}{ Groups } & \multicolumn{2}{c}{ Test statistics } \\
Variables & Intervention $(n=66)$ & Control $(n=66)$ & $t$ & $p$ \\
Age $(m \pm s d)$ & $26.62 \pm 5.44$ & $28.08 \pm 5.32$ & 1.552 & 0.123 \\
& $n(\%)$ & $n(\%)$ & $\chi^{2}$ & $p$ \\
\hline Educational status & & & & \\
Illiterate & $2(3.0)$ & $3(4.5)$ & 3.495 & 0.487 \\
Primary education & $31(47.1)$ & $30(45.6)$ & & \\
High school & $22(33.3)$ & $16(24.2)$ & & \\
Associate's degree & $3(4.5)$ & $9(12.1)$ & & \\
Bachelor's degree & $8(12.1)$ & $6(13.6)$ & & \\
Employment status & & $6(9.1)$ & & \\
Employed & $8(12.1)$ & $60(90.9)$ & 0.378 \\
Unemployed & $58(87.9)$ & $66(100.0)$ & & \\
Total & $66(100.0)$ & & &
\end{tabular}

Note(s): $m$ : mean, $s d$ : standard deviation, $\chi^{2}$ : chi-square test statistic and $t$ : independent two sample $t$-test statistics 


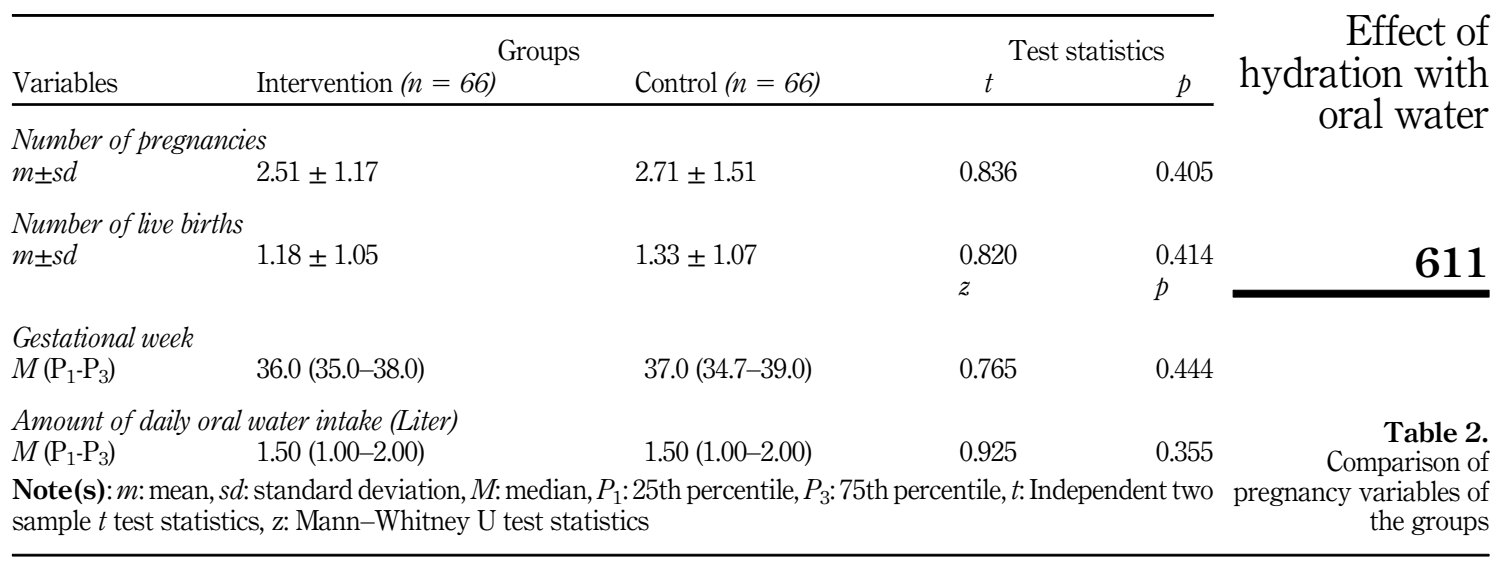

\begin{tabular}{|c|c|c|c|c|}
\hline \multirow[b]{3}{*}{ Variables } & \multicolumn{2}{|c|}{ Groups } & \multirow{2}{*}{\multicolumn{2}{|c|}{ Test statistics }} \\
\hline & Intervention $(n=66)$ & Control $(n=66)$ & & \\
\hline & $n(\%)$ & $n(\%)$ & $\chi^{2}$ & $p$ \\
\hline Variability & & & - & - \\
\hline Available & $66(100.0)$ & $66(100.0)$ & & \\
\hline Not available & $0(0.0)$ & $0(0.0)$ & & \\
\hline Acceleration & & & 0.532 & 0.718 \\
\hline Available & 63 (95.5) & $61(92.4)$ & & \\
\hline Not available & $3(4.5)$ & $5(7.6)$ & & \\
\hline Deceleration & & & 0.496 & 0.597 \\
\hline Available & $26(39.4)$ & 30 (45.5) & & \\
\hline Not available & $40(60.6)$ & $36(54.5)$ & & \\
\hline NST result & & & 3.685 & 0.097 \\
\hline Reactive & $62(93.9)$ & 55 (83.3) & & \\
\hline Nonreactive & $4(6.1)$ & $11(16.7)$ & & \\
\hline Total & $66(100.0)$ & $66(100.0)$ & & \\
\hline
\end{tabular}

Note(s): $\chi^{2}$ : chi-square test statistic

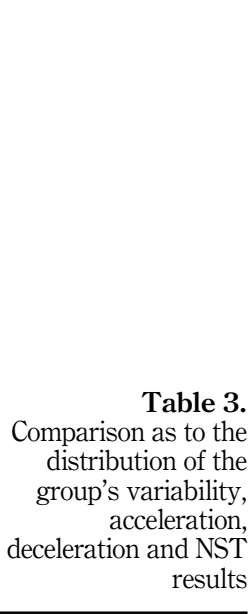

\begin{tabular}{lcccr}
\hline & \multicolumn{2}{c}{ Groups } & \multicolumn{2}{c}{ Test statistics } \\
Variables & $\begin{array}{c}\text { Intervention }(n=66) \\
M\left(P_{1}-P_{3}\right)\end{array}$ & $\begin{array}{c}\text { Control }(n=66) \\
M\left(P_{1}-P_{3}\right)\end{array}$ & $z$ & $p$ \\
\hline Fetal heart rate & $130.0(125.0-135.0)$ & $140.0(130.0-145.0)$ & 4.857 & $<0.001$ \\
*Acceleration & $6.0(4.0-9.0)$ & $4.0(2.0-6.0)$ & 4.446 & $<0.001$ \\
*Deceleration & $1.0(1.0-2.0)$ & $1.0(1.0-2.0)$ & 0.056 & 0.956
\end{tabular}

Note(s): $M$ : median, $P_{1}: 25$ th percentile, $P_{3}:$ 75th percentile, $z$ : Mann-Whitney U test statistics, *Acceleration: intervention $n=63$, control $n=61$, *Deceleration: intervention $n=26$, control $n=30$

Table 4.

Comparison of numbers of fetal heart rate, acceleration and deceleration

\section{Discussion}

This research was carried out to assess the effect of hydration with oral water on NST. As there were not any previous studies about this exact condition, the outcomes of the study were discussed in comparison with other studies about the NST. 
JHR

36,4

612

In this study, pregnant women in the intervention and control groups were similar in age, educational status, employment status, number of pregnancies, number of live births, gestational week and the amount of daily oral water intake.

In this study, it was determined that intervention and control groups were similar in terms of the presence of variability, acceleration and deceleration and in terms of reactivity and nonreactivity. In addition, there was not a statistically significant difference between the groups in the presence of variability, acceleration and deceleration and NST results. In line with this result, "hydration with oral water affects the reactive NST result" hypothesis was rejected. However, it is possible to say that administering hydration with oral water in the intervention group does not constitute any negative impacts on fetal well-being. On the contrary, in the study conducted by Erkun Dolker and Basar, it was determined that music was an effective method of increasing reactive NST rates [20]. In the study conducted by Gebuza et al. analyzing the effect of music on the cardiac activity of a fetus in a cardiotocographic examination, it was determined that there were significant changes in episodes of higher variability after the music was played [23]. In another study conducted by Şimşek Küçükkelepçe and Timur Taşhan analyzing the effect of music on NST results, it was found that the intervention group had higher reactivity in their NST results in comparison with the control group [18].

In this study, a statistically significant result was found between the intervention and control groups in terms of FHR. However, when FHR's of both groups were evaluated, it was seen that they were both within the normal range [24]. When the groups were assessed from the acceleration aspect, it was determined that the intervention group had higher values, and that there was a statistically significant difference between the intervention and control groups. With this finding, it is thought that hydration with oral water tends to increase accelerations in the fetus. It was found that there was no statistical difference between them in terms of deceleration. This finding gives rise to the thought that hydration with oral water does not increase the number of decelerations, so that it does not affect fetal well-being negatively. These results confirmed two hypotheses, "hydration with oral water affects FHR" and "hydration with oral water affects the number of accelerations". However, the hypothesis "hydration with oral water affects the number of decelerations" was rejected. Previous studies have shown that music increases FHR $[25,26]$ and the number of accelerations [18, 26]. In the study conducted by Tranquilli et al., it was determined that eating chocolate significantly increased the number of accelerations, episodes of high variation/min and the short-term variation [27]. Buscicchio et al. found that the number of acceleration and the short-term FHR variation were significantly higher after taking coffee and chocolate [28]. In a study by Esin et al, it was found that the NST results of orange juice and bitter chocolate groups and the control group did not have a statistically significant difference [12]. Findings of this research are similar to the outcomes of the aforementioned studies.

\section{Limitations of the study}

Even though the total amount of water that pregnant women drink daily was questioned in this study, the fact that the amount of water and fluids they received before NST was not questioned can be considered a limitation of the study. Another limitation is that the biophysical profile assessment in the ultrasound was not performed simultaneously.

\section{Conclusion}

It was determined that hydration with oral water prior to the NST created a statistically significant difference between the intervention and control groups in terms of FHR and the number of accelerations. However, FHR's were within the normal range in both groups. In terms of accelerations, it was thought that hydration with oral water prior to the NST tended to increase the number of accelerations. 


\section{References}

1. Samuel R, Karkada S, Fernandes S, Bhat P. Materno foetal physiological parameters in sitting and left lateral position during non - stress test (NST) monitoring in pregnancy: a cross over study. Manipal J Nurs Health Sci. 2015; 1(2): 83-6.

2. Kızılkaya Beji N, Dişsiz M. Pregnancy and nursing approach. In: Kızılkaya Beji N (Ed.). Women's health and diseases intended for nurses and midwives.Istanbul: Nobel Medical Bookstores; 2015: 263-4.

3. Güler S, Avcı S, Yiğit F. Prenatal care and evaluation of fetal health. In: Arslan Özkan H (Ed.). Women's health and diseases for nursing and midwifery. Ankara: Akademisyen bookstore; 2019: 235-9.

4. McKinney ES, James SR, Murray SS, Nelson KA, Ashwill JW. Maternal-child nursing. 5th ed. St. Louis, Missouri: Elsevier; 2018: 274-86.

5. Taşkın L. Obstetrics and women's health nursing. Ankara: Akademisyen bookstore; 2016: 141-45.

6. Aluş Tokat M. Electronic fetal monitoring during pregnancy (antepartum). In: Aluş Tokat M (Ed.). Electronic fetal monitoring in pregnancy and labor, concepts-definitions-examples. Istanbul: Deomed; 2013: 42.

7. EFSA Panel on Dietetic Products, Nutrition, and Allergies [NDA]. Scientific opinion on dietary reference values for water. EFSA Journal. 2010; 8(3): 1459. doi: 10.2903/j.efsa.2010.1459.

8. Gizzo S, Noventa M, Vitagliano A, Dall'Asta A, D'Antona D, Aldrich CJ, et al. An update on maternal hydration strategies for amniotic fluid improvement in isolated oligohydramnios and normohydramnios: evidence from a systematic review of literature and meta-analysis. PLoS One. 2015; 10(12): e0144334. doi: 10.1371/journal.pone.0144334.

9. Mulyani EY, Hardinsyah, BD, Santoso BI. Hydration status of pregnant women in West Jakarta. Asia Pac J Clin Nutr. 2017; 26(Suppl 1): S26-30. doi: 10.6133/apjcn.062017.s14.

10. Ülker K, Çiçek M. Effect of maternal hydration on the amniotic fluid volume during maternal rest in the left lateral decubitus position: a randomized prospective study. J Ultrasound Med. 2013; 32(6): 955-61. doi: 10.7863/ultra.32.6.955.

11. Rawat R, Garg R, Kaushik A, Sachan R. Effect of maternal oral hydration therapy on maternal and perinatal outcome in isolated oligohydramnios. J South Asian Fed Obstet Gynaecol. 2015; 7(2): 64-7. doi: 10.5005/jp-journals-10006-1325.

12. Esin S, Baser E, Cakir C, Ustun Tuncal GN, Kucukozkan T. Chocolate or orange juice for nonreactive non-stress test (NST) patterns: a randomized prospective controlled study. J Matern Fetal Neonatal Med. 2013; 26(9): 915-9. doi: 10.3109/14767058.2013.766698.

13. Esin S. Factors that increase reactivity during fetal nonstress testing. Curr Opin Obstet Gynecol. 2014; 26(2): 61-6. doi: 10.1097/GCO.0000000000000050.

14. Kıratlı D, Yavan T, Karaşahin KE, Yenen MC. The effect of different maternal positions on reactivity of the nonstress test, maternal blood pressure and heart rate. Journal of Dr. Behcet Uz Children's Hospital. 2018; 8(2): 101-8. doi: 10.5222/buchd.2018.101.

15. Mahboubeh V, Masoumeh P, Zahra S. Comparison of vibro-acoustic stimulation and acupressure effects in nonstress test results and its parameters in pregnant women. Iran J Nurs Midwifery Res. 2013; 18(4): 266-71.

16. Pirhadi M, Valiani M. Assessing effects of BL67 points stimulation on fetal heart rate parameters and fetal movements during nonstress test. J Educ Health Promot. 2017; 6: 43. doi: 10.4103/jehp. jehp_120_15.

17. Rahimikian F, Rahiminia T, Modarres M, Mehran A. Comparison of halogen light and vibroacoustic stimulation on nonreactive fetal heart rate pattern. Iran J Nurs Midwifery Res. 2013; 18(2): $112-6$.

18. Şimşek Küçükkelepçe D, Timur Taşhan S. The effect of music on the results of a non-stress test: a non-randomized controlled clinical trial. Eur J Integr Med. 2018; 18: 8-12. doi: 10.1016/j.eujim.2018. 01.002 .

\section{Effect of \\ hydration with oral water}


JHR

36,4

614
19. Essa RM, Hafez Sk. Effect of different positions of pregnant women on their comfort and fetal cardiotocographic patterns during non-stress test. Int J Res Health Sci Nurs. 2018; 4(2): 1-24.

20. Erkun Dolker H, Basar F. The effect of music on the non-stress test and maternal anxiety. Complement Ther Clin Pract. 2019; 35: 259-64. doi: 10.1016/j.ctcp.2019.03.007.

21. Zhou Y, Zhu X, Qin Y, Li Y, Zhang M, Liu W, et al. Association between total water intake and dietary intake of pregnant and breastfeeding women in China: a cross-sectional survey. BMC Pregnancy Childbirth. 2019; 19(1): 172. doi: 10.1186/s12884-019-2301-z.

22. Bardosono S, Prasmusinto D, Hadiati DR, Purwaka BT, Morin C, Pohan R, et al. Fluid intake of pregnant and breastfeeding women in Indonesia: a cross-sectional survey with a seven-day fluid specific record. Nutrients. 2016; 8(11): 651. doi: 10.3390/nu8110651.

23. Gebuza G, Zaleska M, Kazmierczak M, Mieczkowska E, Gierszewska M. The effect of music on the cardiac activity of a fetus in a cardiotocographic examination. Adv Clin Exp Med. 2018; 27(5): 615-21. doi: 10.17219/acem/68693.

24. NSW Government. Maternity - fetal heart rate monitoring. [updated 2018 Dec 19; cited 2020 Nov]. Available from: https://www1.health.nsw.gov.au/pds/ActivePDSDocuments/GL2018_025.pdf.

25. Garcia Gonzalez J, Ventura Miranda MI, Manchon Garcia F, Pallares Ruiz TI, Marin Gascon ML, Requena Mullor M, et al. Effects of prenatal music stimulation on fetal cardiac state, newborn anthropometric measurements and vital signs of pregnant women: a randomized controlled trial. Complement Ther Clin Pract. 2017; 27: 61-7. doi: 10.1016/j.ctcp.2017.03.004.

26. Kafali H, Derbent A, Keskin E, Simavli S, Gözdemir E. Effect of maternal anxiety and music on fetal movements and fetal heart rate patterns. J Matern Fetal Neonatal Med. 2011; 24(3): 461-4. doi: 10.3109/14767058.2010.501122.

27. Tranquilli AL, Lorenzi S, Buscicchio G, Di Tommaso M, Mazzanti L, Emanuelli M. Female fetuses are more reactive when mother eats chocolate. J Matern Fetal Neonatal Med. 2014; 27(1): 72-4. doi: 10.3109/14767058.2013.804053.

28. Buscicchio G, Piemontese M, Gentilucci L, Ferretti F, Tranquilli AL. The effects of maternal caffeine and chocolate intake on fetal heart rate. J Matern Fetal Neonatal Med. 2012; 25(5): 528-30. doi: 10.3109/14767058.2011.636104.

\section{Corresponding author}

Yeter Şener can be contacted at: hem_yetersener@hotmail.com

For instructions on how to order reprints of this article, please visit our website:

www.emeraldgrouppublishing.com/licensing/reprints.htm

Or contact us for further details: permissions@emeraldinsight.com 